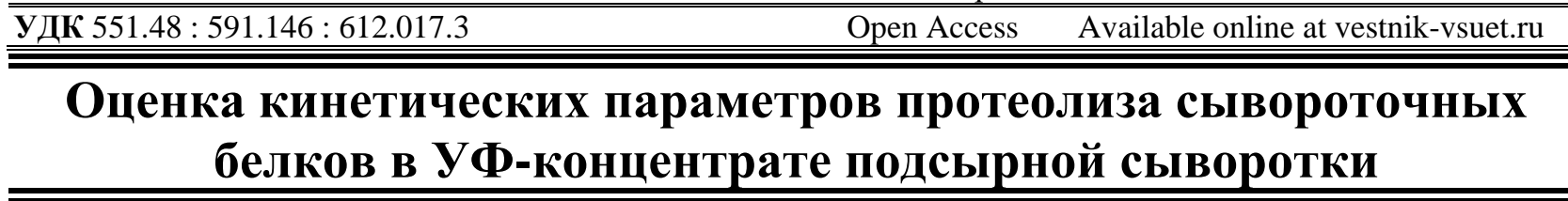

\begin{tabular}{llll}
\hline \hline Елена И. Мельникова & 1 & melnikova@molvest.ru & (1) 0000-0002-3474-2534 \\
Екатерина В. Богданова & ${ }^{1}$ & ek-v-b@yandex.ru $^{(D)}$ 0000-0001-5053-2273
\end{tabular}

1 Воронежский государственный университет инженерных технологий, пр-т Революции, 19, г. Воронеж, 394036, Россия Аннотация. Цель работы - обоснование выбора ферментных препаратов Promod 523MDP, Promod 439L, Flavorpro 766MDP, Flavorpro 750MDP (производитель - Biocatalysts Limited, Великобритания) и определение эффективного времени гидролиза сывороточных белков в ультрафильтрационном концентрате (УФ-концентрате) подсырной сыворотки для снижения их аллергенности на основании анализа кинетических констант реакции протеолиза. Экспериментальные исследования проводили с образцами УФ-концентрата подсырной сыворотки с массовой долей общего белка не менее $3,0 \%$, полученными на промышленной ультрафильтрационной установке MMS Swissflow UF с керамическими мембранами в условиях ПАО МК «Воронежский». Предварительно их подвергали ферментативному гидролизу в течение 8 ч при постоянной температуре, исходя из данных по дозировке, оптимума $\mathrm{pH}$ и температуры используемых ферментов, рекомендованных производителем. Для оценки эффективности действия применяемых ферментных препаратов использовали константу «специфичности» $V_{\text {max }} / \mathrm{K}_{\mathrm{m}}$, характеризующую константы всех стадий реакции гидролиза. Сделан вывод о том, что изученные ферментные препараты с достаточной эффективностью могут быть использованы для гидролиза сывороточных белков УФ-концентрата подсырной сыворотки. Наиболее высокой скоростью протеолиза характеризуется смесь Promod 439L и Flavorpro 766MDP в соотношении 1,5 и $3,0 \%$ соответственно от общего содержания белка в субстрате. По результатам микроскопирования доказано увеличение растворимости азотсодержащих компонентов после гидролиза вследствие уменьшения на поверхности пептидов гидрофобных участков. Полученный гидролизат может быть реализован в технологии широкого ассортимента молочных и кисломолочных продуктов для снижения их остаточной антигенности путем частичной замены в рецептуре обезжиренного молока.

Ключевые слова: протеолиз, скорость гидролиза, константа специфичности, снижение аллергенности, сывороточные белки

\title{
Estimation of the kinetic parameters of whey proteins proteolysis in the UF-concentrate of cheese whey
}

\begin{tabular}{|c|c|c|}
\hline & & \\
\hline \multicolumn{3}{|c|}{ zh State University of Engineering Technologies, Revolution Av., 19 Voronezh, 394036, Russia } \\
\hline \multicolumn{3}{|c|}{$\begin{array}{l}\text { Abstract. The purpose of the research is to substantiate the choice of enzyme preparations Promod 523MDP, Promod 439L, Flavorpro } \\
\text { 766MDP, and Flavorpro 750MDP (Biocatalysts Limited, UK) and to determine the effective time of whey proteins hydrolysis in an } \\
\text { ultrafiltration concentrate (UF-concentrate) of cheese whey for reducing their allergenicity based on the analysis of kinetic constants } \\
\text { of the proteolysis reaction. Experimental studies were carried out with samples of cheese whey UF-concentrate with a total protein } \\
\text { mass fraction at least } 3.0 \% \text { obtained with the use of industrial ultrafiltration unit MMS Swissflow UF with ceramic membranes under } \\
\text { the conditions of the PSC Dairy Plant "Voronezhskii". They were preliminarily subjected to enzymatic hydrolysis for } 8 \text { hours at a } \\
\text { constant temperature, based on the dosage data, the optimum pH and the temperature of the used enzymes, recommended by the } \\
\text { manufacturer. The specificity constant } V_{\text {max }} / K_{m} \text { was used to estimate the effectiveness of the enzyme preparations, which characterizes } \\
\text { the constants of all stages of the hydrolysis reaction. The highest proteolysis rate has a mixture of Promod } 439 \mathrm{~L} \text { and Flavorpro } 766 \mathrm{MDP} \\
\text { in the ratio of } 1.5 \text { and } 3.0 \% \text {, respectively, of the total protein content in the substrate. Microscopy results showed an increasing in the } \\
\text { solubility of nitrogen-containing components after hydrolysis due to a decreasing in hydrophobic areas on the surface of peptides. The } \\
\text { resulting hydrolysate can be applied in the technology of a wide range of dairy products to reduce their residual antigenicity by partially } \\
\text { replacing skim milk in the formulation. }\end{array}$} \\
\hline
\end{tabular}

\section{Введение}

Белки имеют важное значение в пищевом рационе человека, поэтому их получают из различных сырьевых источников и применяют при производстве продуктов питания. Однако ассортиментные группы пищевых продуктов для обогащения зачастую ограничены свойствами, которыми характеризуются белки.

\section{Для цитирования}

Мельникова Е.И., Богданова Е.В. Оценка кинетических параметров протеолиза сывороточных белков в УФ-концентрате подсырной сыворотки // Вестник ВГУИТ. 2020. Т. 82. № 4. С. 107-112. doi:10.20914/2310-1202-2020-4-107-112

\section{(C) 2021, Мельникова Е.И. и др. / Melnikova E.I. et al.}

Их направленное изменение возможно посредством различных способов, одним из которых является ферментативный гидролиз. Этот способ широко используется в пищевой промышленности, особенно при получении низкоаллергенных заменителей грудного молока и хорошо растворимых пептидных фракций для обогащения различных пищевых продуктов $[1,2,3]$.

For citation

Melnikova E.I., Bogdanova E.V. Estimation of the kinetic parameters of whey proteins proteolysis in the UF-concentrate of cheese whey. Vestnik VGUIT [Proceedings of VSUET]. 2020. vol. 82. no. 4. pp. 107-112. (in Russian). doi:10.20914/2310-1202-2020-4-107-112

This is an open access article distributed under the terms of the Creative Commons Attribution 4.0 International License 
Микробиологические протеазы охватывают широкий спектр ферментов, воздействующих на пептидные связи в молекулах белков и пептидов [4]. Некоторые из них способны разрывать только специфические связи между определенными $\alpha$-аминокислотами на $\mathrm{N}$ - или С-терминальных участках или внутри пептидных цепей. При этом важное значение для проведения направленного протеолиза представляет совместное использование эндо- и экзопептидаз. Первые участвуют в расщеплении белков на олигопептиды, вторые, проявляя свойства амино- или дипептидаз, разрушают образующиеся молекулы до свободных $\alpha$-аминокислот.

Важным сырьевым источником полноценных белков животного происхождения является подсырная сыворотка, объемы получения которой на молочных предприятиях значительно возросли за последние несколько лет [5]. Молекулы сывороточных белков содержат ряд последовательностей аминокислот, близких к составу белков мышечной ткани человека. Также они превосходят все известные белки животного и растительного происхождения по количеству в молекулах аминокислот с разветвленной цепью (лейцина и изолейцина, валина) и общему количеству незаменимых аминокислот (метионина, триптофана, лизина, треонина). Фактором, ограничивающим применение сывороточных белков в пищевых технологиях, является их аллергенность [6, 7]. Значительной аллергенностью среди всех сывороточных белков характеризуется $\beta$-лактоглобулин.

В этой связи проведены исследования по снижению антигенности сывороточных белков подсырной сыворотки в результате ферментативного гидролиза с применением различных высокоспецифичных протеаз: Promod 523MDP, Promod 439L, Flavorpro766MDP и Flavorpro 750MDP (производитель - Biocatalysts Limited, Великобритания). Promod 523MDP - нейтральная протеаза, которую используют для эффективного гидролиза $\beta$-лактоглобулина. Promod 439L протеаза, субстратом для которой является как $\beta$-лактоглобулин, так и $\alpha$-лактоальбумин. Flavorpro766 MDP - ферментный препарат, который может проявлять свойства как экзо-, так и эндопептидазы, отщепляя аминокислоты с высокой гидрофобностью и снижая таким образом горечь образующихся пептидов. Flavorpro 750MDP - протеаза, применяемая для контроля длины образующихся при гидролизе белков пептидов и снижения их горечи.

Цель работы - обоснование выбора ферментных препаратов и определение эффективного времени гидролиза сывороточных белков в ультрафильтрационном концентрате (УФконцентрате) подсырной сыворотки для снижения их аллергенности на основании анализа кинетических констант реакции протеолиза.

\section{Материалы и методы}

Экспериментальные исследования проводили с образцами УФ-концентрата подсырной сыворотки с массовой долей общего белка не менее 3,0\%, полученными на промышленной ультрафильтрационной установке MMS Swissflow UF с керамическими мембранами в условиях ПАО МК «Воронежский» [8]. Предварительно их подвергали ферментативному гидролизу в течение 8 ч при постоянной температуре в условиях кафедры технологии продуктов животного происхождения ФГБОУ ВО ВГУИТ, исходя из данных по дозировке, оптимума $\mathrm{pH}$ и температуры используемых ферментов, рекомендованных производителем. Поскольку активная кислотность исследуемой смеси изменялась в связи с высвобождением аминои карбоксильных групп, протеолиз проводили в буферной системе, уровень $\mathrm{pH}$ поддерживали внесением растворов кислоты или щелочи. С целью инактивации ферментов по окончании гидролиза образцы подвергали тепловой обработке при $t=(80 \pm 2){ }^{\circ} \mathrm{C}$ с выдержкой не менее $\tau=5$ мин.

Для изучения основных кинетических характеристик протеолиза сывороточных белков в УФ-концентрате подсырной сыворотки была применена модель А.И. Костнера, С.В. Богаткова и А.Д. Неклюдова [9]. Кинетические константы реакции гидролиза рассчитывали по уравнениям $[10,11,12]$ :

$$
\begin{gathered}
V_{t}=\frac{P}{t}=V_{\max } \cdot e^{-K t}, \\
\ln V=\ln \left(\frac{P}{t}\right)=\ln V_{\max }-K_{i} \cdot t, \\
K_{M}=\frac{V_{\max }}{K_{i}},
\end{gathered}
$$

где $P$ - концентрация в 1 л реакционной смеси расщепленных пептидных связей к моменту времени $t$, выраженная в граммах условного азота свободных аминогрупп (г/л); $V_{\max }$ - максимальная скорость гидролиза, моль/л·с; $K_{i}$ - константа специфичности,

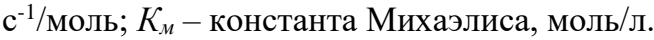

Скорость ферментативной реакции находили с помощью графоаналитического метода с применением линейного преобразования уравнения Михаэлиса-Ментен в зависимость Эди-Скетчарда [13]. Течение реакции контролировали по изменению концентрации небелкового азота в исследуемых образцах методом Къельдаля в соответствии с ГОСТ Р 55246-2012. Ввиду присутствия нескольких потенциальных субстратов в реакционной смеси ( $\beta$-лактоглобулин, $\alpha$-лактоальбумин, иммуноглобулины) каталитическую эффективность исследуемых ферментов оценивали по константе специфичности $V_{\max } / K_{m}$. Ее максимальное значение определяется частотой столкновений субстрата и фермента, 
приводящих к образованию фермент-субстратного комплекса, что, в свою очередь, прямо пропорционально скорости диффузии реагирующих веществ в растворе. Эта величина важна для анализа особенностей образования фермент-субстратного комплекса при наличии избытка активных центров связывания субстрата, что позволяет непосредственно оценить эффективность работы фермента при взаимодействии с различными субстратами.

Микроскопические исследования образцов проводили с препаратом «раздавленная капля» с применением микроскопа «Альтами Био 1», фотонасадка Canon) при увеличении в 600/0,85 раз.

В ходе выполнения эксперимента при определении каждого показателя проведены 5 - 10 опытов в трехкратной последовательности с последующей обработкой полученных результатов методами математической статистики с использованием пакета прикладных программ «MathCad 16.0».

\section{Результаты и обсуждение}

В процессе ферментативного гидролиза происходило накопление пептидов и свободных аминокислот (таблица 1). При этом наиболее полно гидролиз протекал при совместном

использовании эндопептидазы Promod 439L и экзопептидаз Flavorpro 766MDP и Flavorpro 750MDP.

Полученные результаты, выраженные как функция скоростей гидролиза во времени $[P / t=f(t)]$, представляют собой гиперболические кривые. Проведена их линеаризация, позволившая преобразовать их в прямые псевдопервого порядка (рисунок 1). На них условно можно выделить 2 стадии процесса: «быструю» (первые 3 ч) и «медленную» (3-8 ч), в течение которых происходит накопление приблизительно равных количеств небелкового азота. Снижение скорости реакции на второй стадии протеолиза обусловлено насыщением системы продуктами реакции и достижением стационарной фазы. На основании данных рисунка 1 рассчитаны максимальные скорости реакции и эффективное время ферментативного гидролиза: точки пересечения линейных отрезков при экстраполяции с осью ординат соответствуют максимальным скоростям гидролиза $\left(V_{\max }\right)$, а с осью абсцисс - эффективному времени гидролиза [12].

\section{Таблица 1 .}

Изменение содержания небелкового азота в образцах в процессе протеолиза

Table 1.

Change in non-protein nitrogen content in samples during proteolysis

\begin{tabular}{|c|c|c|c|c|c|c|c|c|}
\hline \multirow{2}{*}{$\begin{array}{l}\text { Продолжительность } \\
\text { гидролиза, мин } \\
\text { Duration of hydrolysis, } \\
\text { min }\end{array}$} & \multicolumn{8}{|c|}{$\begin{array}{c}\text { Содержание небелкового азота в пробе, полученной с применением ферментных } \\
\text { препаратов, \% } \\
\text { Non-protein nitrogen content in a sample obtained using enzyme preparations, } \%\end{array}$} \\
\hline & $\begin{array}{l}\text { Promod } \\
523 \mathrm{MDP}\end{array}$ & $\begin{array}{c}\text { Promod } \\
439 \mathrm{~L}\end{array}$ & $\begin{array}{l}\text { Flavorpro } \\
\text { 766MDP }\end{array}$ & $\begin{array}{l}\text { Flavorpro } \\
\text { 750MDP }\end{array}$ & \begin{tabular}{|c|} 
Promod \\
$523 \mathrm{MDP}+$ \\
Flavorpro \\
$750 \mathrm{MDP}$
\end{tabular} & $\begin{array}{l}\text { Promod } \\
439 \mathrm{~L}+ \\
\text { Flavorpro } \\
\text { 766MDP }\end{array}$ & $\begin{array}{l}\text { Promod } \\
\text { 523MDP + } \\
\text { Flavorpro } \\
\text { 766MDP }\end{array}$ & $\begin{array}{l}\text { Promod } \\
\text { 439L + } \\
\text { Flavorpro } \\
\text { 750MDP }\end{array}$ \\
\hline 0 & 0,094 & 0,094 & 0,094 & 0,094 & 0,094 & 0,094 & 0,094 & 0,094 \\
\hline 30 & 0,098 & 0,101 & 0,097 & 0,095 & 0,103 & 0,108 & 0,105 & 0,105 \\
\hline 60 & 0,107 & 0,112 & 0,103 & 0,099 & 0,115 & 0,125 & 0,118 & 0,122 \\
\hline 90 & 0,125 & 0,130 & 0,113 & 0,107 & 0,129 & 0,147 & 0,133 & 0,144 \\
\hline 120 & 0,139 & 0,148 & 0,126 & 0,117 & 0,150 & 0,164 & 0,156 & 0,159 \\
\hline 150 & 0,161 & 0,175 & 0,141 & 0,129 & 0,176 & 0,205 & 0,181 & 0,192 \\
\hline 180 & 0,183 & 0,196 & 0,158 & 0,142 & 0,202 & 0,251 & 0,213 & 0,235 \\
\hline 240 & 0,195 & 0,208 & 0,175 & 0,158 & 0,233 & 0,288 & 0,238 & 0,272 \\
\hline 300 & 0,203 & 0,217 & 0,185 & 0,166 & 0,249 & 0,311 & 0,252 & 0,287 \\
\hline 360 & 0,210 & 0,224 & 0,191 & 0,175 & 0,262 & 0,321 & 0,275 & 0,297 \\
\hline 420 & 0,212 & 0,228 & 0,193 & 0,177 & 0,266 & 0,326 & 0,278 & 0,301 \\
\hline 480 & 0,215 & 0,231 & 0,194 & 0,178 & 0,268 & 0,329 & 0,280 & 0,303 \\
\hline
\end{tabular}

Для оценки эффективности действия применяемых ферментных препаратов использовали константу специфичности $V_{\max } / \mathrm{K}_{\mathrm{m}}$, характеризующую константы всех стадий реакции гидролиза. Анализ средних численных значений кинетических параметров реакции протеолиза (таблица 2) позволяет прийти к заключению, что изученные ферментные препараты с достаточной эффективностью могут быть использованы для гидролиза сывороточных белков УФ-концентрата подсырной сыворотки. При этом высокая скорость протеолиза, вероятно, обусловлена низкой энергией активации. В этой связи полученные гидролизаты могут характеризоваться высоким содержанием короткоцепочечных пептидов с низкой гидрофобностью, обусловливающей горький вкус конечного продукта [14]. 


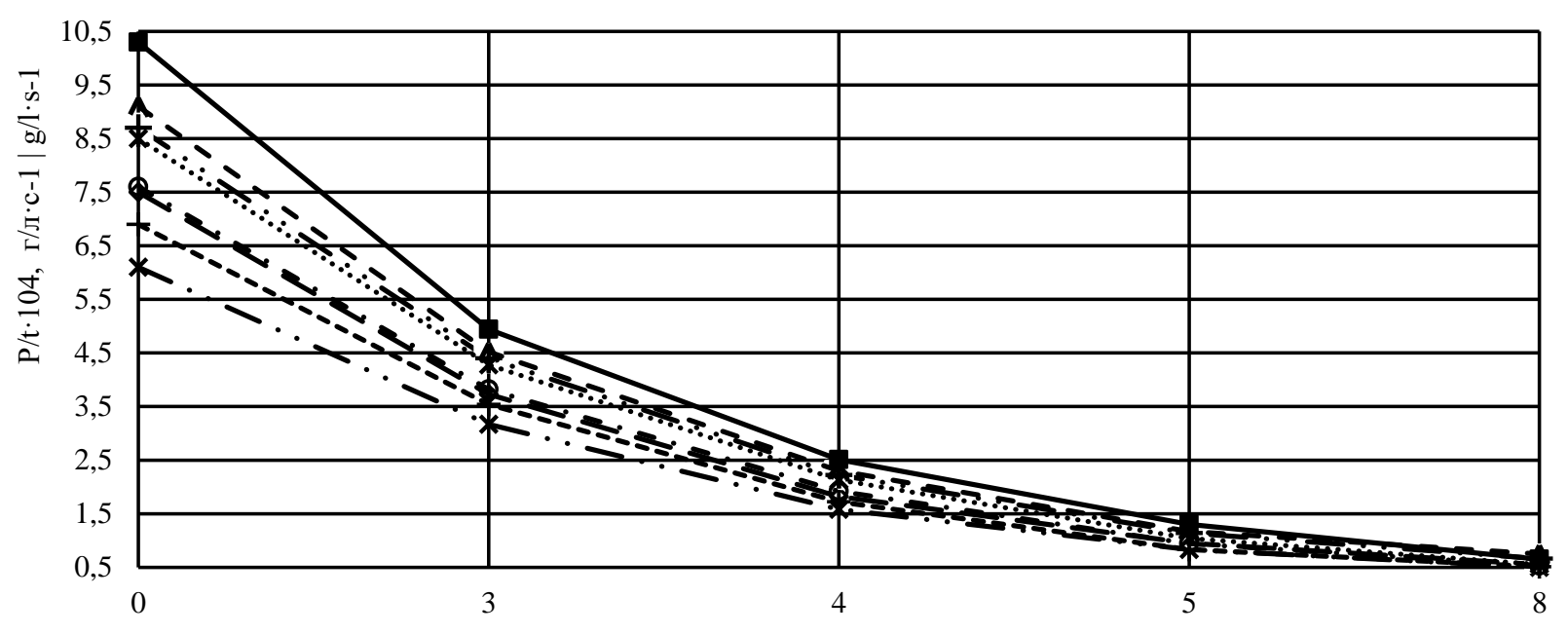

Продолжительность гидролиза белков УФ-концентрата, ч, под действием ферментных препаратов:

Duration of hydrolysis, h, under the action of enzyme preparations:

-×・ P Promod 523MDP
-+・ - Flavorpro 766MDP
--+-・ Promod 523MDP + Flavorpro 750MDP
- o- Promod 523MDP + Flavorpro 766MDP

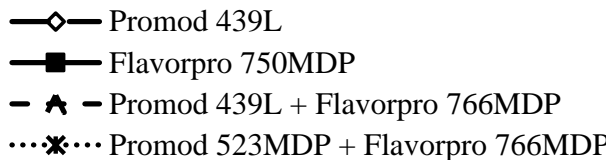

Рисунок 1. Изменение скорости ферментативной реакции в процессе гидролиза

Figure 1. Change in the rate of enzymatic reaction during hydrolysis

Таблица 2 .

Кинетические параметры реакции протеолиза различными препаратами

Table 2.

Kinetic parameters of the proteolysis reaction by various enzymes

\begin{tabular}{|c|c|c|}
\hline $\begin{array}{c}\text { Ферментный препарат } \\
\text { Enzyme }\end{array}$ & $\begin{array}{c}\text { Максимальная скорость реакции } \\
\text { Махіmum reaction rate } \\
\mathrm{V}_{\max } \cdot 10^{-4}, \mathrm{~g} \cdot \mathrm{l}^{-1} \cdot \mathrm{s}^{-1}\end{array}$ & $\begin{array}{c}\text { Константа «специфичности» } \\
\text { Specificity constant } \\
V_{\max } / \mathrm{K}_{\mathrm{m}}, \mathrm{s}^{-1} / \mathrm{mmol}\end{array}$ \\
\hline Promod 523MDP & $6,1 \pm 0,4$ & 2011 \\
\hline Promod 439L & $7,5 \pm 0,3$ & 3785 \\
\hline Flavorpro 766MDP & $8,7 \pm 0,2$ & 1438 \\
\hline Flavorpro 750MDP & $10,3 \pm 0,2$ & 2910 \\
\hline Promod 523MDP + Flavorpro 750MDP & $6,9 \pm 0,3$ & 2561 \\
\hline Promod 439L + Flavorpro 766MDP & $9,1 \pm 0,2$ & 4237 \\
\hline Promod 523MDP + Flavorpro 766MDP & $7,6 \pm 0,3$ & 1824 \\
\hline Promod 439L + Flavorpro 750MDP & $8,5 \pm 0,2$ & 3973 \\
\hline
\end{tabular}

В процессе гидролиза ферментными препаратами с максимальной скоростью гидролиза возможно также образование значительного количества свободных аминокислот, которые помимо отрицательного влияния на органолептические свойства могут приводить к увеличению осмотичности гидролизатов и снижению их биологической ценности, поскольку скорость всасывания свободных аминокислот в тонком кишечнике человека существенно ниже по сравнению с олигопептидами [15]. Поэтому на основании проведенных исследований сделан вывод о целесообразности применения ферментных препаратов Promod 439L и Flavorpro
766MDP для эффективного гидролиза сывороточных белков в УФ-концентрате подсырной сыворотки в количестве 1,5 и $3,0 \%$ соответственно от общего содержания белка в субстрате.

Поскольку полученный гидролизат планируется применять в технологии молочных продуктов для частичной замены обезжиренного молока в нормализованной смеси и снижения таким образом их аллергенности, важной его характеристикой является растворимость азотсодержащих компонентов. Этот показатель значительно увеличивается с повышением степени гидролиза, что обусловлено изменением заряда белков и пептидов (рисунок 2). 


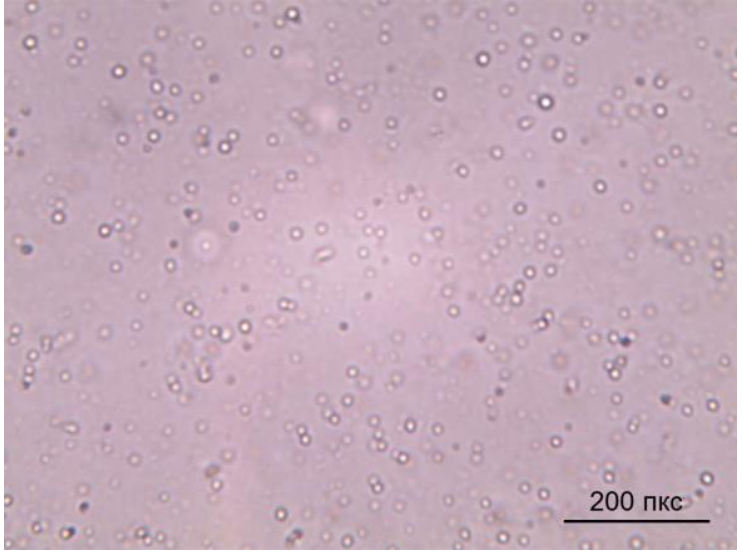

(a)

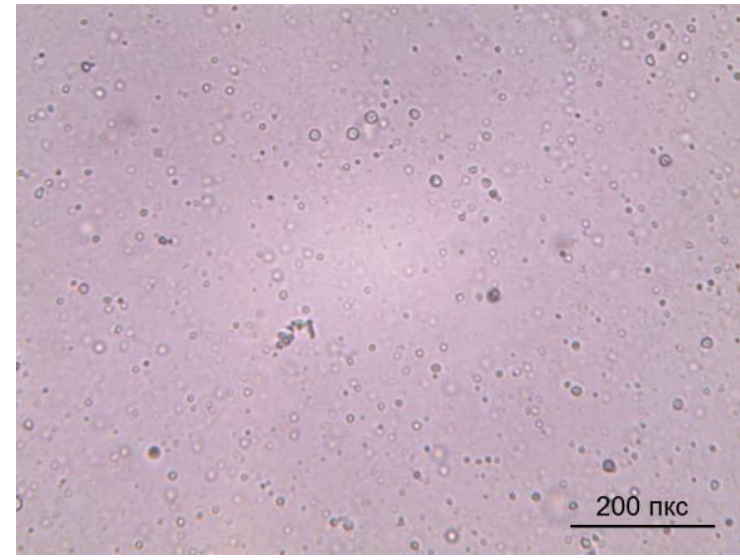

(b)

Рисунок 2. Микроструктура изученных образцов (увеличение 600/0,85): а) УФ-концентрат подсырной сыворотки; б) гидролизат сывороточных белков, полученный с применением ферментных препаратов Flavorpro 766MDP и Promod 439L

Figure 2. Microstructure of the studied samples (magnification 600/0.85): a) UF-concentrate of cheese whey; b) hydrolysate of whey proteins obtained with the use of enzyme preparations Flavorpro 766MDP and Promod 439L

При снижении на поверхности пептидов гидрофобных участков общая растворимость азотсодержащих компонентов увеличивается.

\section{Заключение}

Полученный гидролизат может быть реализован в технологии широкого ассортимента молочных и кисломолочных продуктов для снижения их остаточной антигенности путем частичной замены в рецептуре обезжиренного молока.

\section{Благодарности}

Работа осуществлялась в рамках гранта Президента РФ на 2020-2021 гг. для молодых ученых - кандидатов наук, соглашение № 075-152020-322 (МК-1267.2020.11).

\section{Литература}

1 Contesini F.J., de Melo R.R., Sato H.H. An overview of Bacillus proteases: from production to application // Critical Reviews in Biotechnology. 2018. V. 38. № 3. P. 321-334. doi:10.1080/07388551.2017.1354354.

2 Kostenko K., Bratsikhin A., Borisenko A., Salmanova D. et al. Computer modeling of whey protein $\beta$-lactoglobulin behavior in the activated liquid systems // Journal of Hygienic Engineering and Design. 2017. V. 20. P. 70-74.

3 Vorob'ev M.M. Proteolysis of $\beta$-lactoglobulin by trypsin: simulation by two-step model and experimental verification by intrinsic tryptophan // Fluorescence Symmetry. 2019. V. 11. P. 153. doi:10.3390/sym11020153.

4 Толкачева А.А., Черенков Д.А., Корнеева О.С., Пономарев П.Г. Ферменты промышленного назначения обзор рынка ферментных препаратов и перспективы его развития // Вестник ВГУИТ. 2017. Т. 79. № 4 (74). С. $197-203$. doi: 10.20914/2310-1202-2017-4-197-203.

5 Рябцева С.А., Храмцов А.Г., Будкевич Р.О., Анисимов Г.С. и др. Физиологические эффекты, механизмы действия и применение лактулозы // Вопросы питания. 2020. Т. 89. № 2. С. 5-20. doi: 10.24411/0042-8833-2020-10012.

6 Vorob'ev M.M., Raob N.M., Kochetkova K.A. Kinetic modeling of demasking and hydrolysis of peptide bonds during proteolysis of $\beta$-lactoglobulin by trypsin // Doklady Akademii Nauk. 2016. V. 471. № 4. P. 487-491.

7 Пономарева Н.В., Мельникова Е.И., Богданова Е.В. Биоконверсия молочных белков для снижения остаточной антигенности // Биотехнология. 2015. Т. 31. № 1. С. 70-74.

8 Мельникова Е.И., Пономарева Н.В. Состав и свойства гидролизата $\beta$-лактоглобулина со сниженной остаточной антигенностью // Молочная промышленность. 2015. № 8. С. 46-47.

9 Souza P.M., Aliakbarian B., Ferreira Filho E.X., Magalhães P.O. et al. Kinetic and thermodynamic studies of a novel acid protease from Aspergillus foetidus // International Journal of Biological Macromolecules. 2015. V. 81. № 11. P. 17-21.

10 Choi B., Rempala G.A., Kim J.K. Beyond the Michaelis-Menten equation: accurate and efcient estimation of enzyme kinetic parameters // Scientific reports. 2017. V. 17018. doi:10.1038/s41598-017-17072-Z.

11 Schulte P.M. The effects of temperature on aerobic metabolism: towards a mechanistic understanding of the responses of ectotherms to a changing environment // Journal of Experimental Biology. 2015. V. 218. P. 1856-1866. doi: 10.1242/jeb.118851.

12 Виннов А., Баль-Прилипко Л. Выбор ферментов для гидролиза промышленных белковых субстратов // Продовольственная индустрия АПК. 2013. № 3 (23). С. 9-13.

13 Zainol N., Ismail S.N. Evaluation of enzyme kinetic parameters to produce methanol using Michaelis-Menten equation // Bulletin of Chemical Reaction Engineering \& Catalysis. 2019. V. 14. № 2. P. 436-442. doi: 10.9767/bcrec.14.2.3317.436-442.

14 Acquah C., Stefano E.D., Udenigwe C.C. Role of hydrophobicity in food peptide functionality and bioactivity // Journal of Food Bioactives. 2018. V. 4. P. 88-98. doi: 10.31665/JFB.2018.4164

15 MacDonald A., Singh R.H., Rocha J.C., van Spronsen F.J. Optimising amino acid absorption: essential to improve nitrogen balance and metabolic control in phenylketonuria // Nutrition Research Reviews. 2019. V. 32 (1). P. 70-78. doi: $10.1017 /$ S0954422418000173. 


\section{References}

1 Contesini F.J., de Melo R.R., Sato H.H. An overview of Bacillus proteases: from production to application. Critical Reviews in Biotechnology. 2018. vol. 38. no. 3. pp. 321-334. doi:10.1080/07388551.2017.1354354.

2 Kostenko K., Bratsikhin A., Borisenko A., Salmanova D. et al. Computer modeling of whey protein $\beta$-lactoglobulin behavior in the activated liquid systems. Journal of Hygienic Engineering and Design. 2017. vol. 20. pp. 70-74.

3 Vorob'ev M.M. Proteolysis of $\beta$-lactoglobulin by trypsin: simulation by two-step model and experimental verification by intrinsic tryptophan. Fluorescence Symmetry. 2019. vol. 11. pp. 153. doi:10.3390/sym11020153.

4 Tolkacheva A.A., Cherenkov D.A., Korneeva O.S., Ponomarev P.G. Industrial enzymes - overview of the market for enzyme preparations and prospects for its development. Proceedings of VSUET. 2017. vol. 79. no. 4 (74). pp. 197-203. doi: 10.20914/2310-1202-2017-4-197-203. (in Russian).

5 Ryabtseva S.A., Khramtsov A.G., Budkevich R.O., Anisimov G.S. et. al. Physiological effects, mechanisms of action and application of lactulose. Voprosy Pitaniya. 2020. vol. 89. no. 2. pp. 5-20. doi: 10.24411/0042-8833-2020-10012. (in Russian).

6 Vorob'ev M.M., Raob N.M., Kochetkova K.A. Kinetic modeling of demasking and hydrolysis of peptide bonds during proteolysis of $\beta$-lactoglobulin by trypsin. Doklady Akademii Nauk. 2016. vol. 471. no. 4. pp. 487-491.

7 Ponomareva N.V., Mel'nikova E.I., Bogdanova E.V. Bioconversion of milk proteins in order to reduce residual antigenicity. Biotechnology. 2015. vol. 31. no. 1. pp. 70-74.

8 Ponomareva N.V. Melnikova E.I. Composition and properties of $\beta$-lactoglobulin hydrolysate with reduced residual antigenicity. Dairy Industry. 2015. no. 8. pp. 46-47. (in Russian).

9 Souza P.M., Aliakbarian B., Ferreira Filho E.X., Magalhães P.O. et al. Kinetic and thermodynamic studies of a novel acid protease from Aspergillus foetidus. International Journal of Biological Macromolecules. 2015. vol. 81. no. 11. pp. 17-21.

10 Choi B., Rempala G.A., Kim J.K. Beyond the Michaelis-Menten equation: accurate and efcient estimation of enzyme kinetic parameters. Scientific Reports. 2017. vol. 17018. doi:10.1038/s41598-017-17072-z.

11 Schulte P.M. The effects of temperature on aerobic metabolism: towards a mechanistic understanding of the responses of ectotherms to a changing environment. Journal of Experimental Biology. 2015. vol. 218. pp. 1856-1866. doi: 10.1242/jeb.118851.

12 Vinnov A., Bal'-Prilipko L. Selection of enzymes for hydrolysis of industrial protein substrates. Food Industry of the Agroindustrial Complex. 2013. no. 3 (23). pp. 9-13. (in Russian).

13 Zainol N., Ismail S.N. Evaluation of enzyme kinetic parameters to produce methanol using Michaelis-Menten equation. Bulletin of Chemical Reaction Engineering \& Catalysis. 2019. vol. 14. no. 2. pp. 436-442. doi: 10.9767/bcrec.14.2.3317.436-442.

14 Acquah C., Stefano E.D., Udenigwe C.C. Role of hydrophobicity in food peptide functionality and bioactivity. Journal of Food Bioactives. 2018. vol. 4. pp. 88-98. doi: 10.31665/JFB.2018.4164.

15 MacDonald A., Singh R.H., Rocha J.C., van Spronsen F.J. Optimising amino acid absorption: essential to improve nitrogen balance and metabolic control in phenylketonuria. Nutrition Research Reviews. 2019. vol. 32 (1). pp. 70-78. doi: 10.1017/S0954422418000173.

\section{Сведения об авторах}

Елена И. Мельникова д.т.н., профессор, кафедра технологии продуктов животного происхождения, Воронежский государственный университет инженерных технологий, пр-т Революции, 19, г. Воронеж, 394036, Россия, melnikova@ molvest.ru Dhttps://orcid.org/0000-0002-3474-2534

Екатерина В. Богданова к.т.н., доцент, кафедра технологии продуктов животного происхождения, Воронежский государственный университет инженерных технологий, пр-т Революции, 19, г. Воронеж, 394036, Россия, ek-v-b@yandex.ru (iDhttps://orcid.org/0000-0001-5053-2273

\section{Вклад авторов}

Елена И. Мельникова консультация в ходе исследования Екатерина В. Богданова написала рукопись, корректировала её до подачи в редакцию и несет ответственность за плагиат

\section{Конфликт интересов}

Авторы заявляют об отсутствии конфликта интересов.

\section{Information about authors}

Elena I. Melnikova Dr. Sci. (Engin.), professor, animal-derived food technology department, Voronezh State University of Engineering Technologies, Revolution Av., 19 Voronezh, 394036, Russia,melnikova@molvest.ru

(D)https://orcid.org/0000-0002-3474-2534

Ekaterina V. Bogdanova Cand. Sci. (Engin.), associate professor, animal-derived food technology department, Voronezh State University of Engineering Technologies, Revolution Av., 19 Voronezh, 394036, Russia, ek-v-b@yandex.ru

(Dhttps://orcid.org/0000-0001-5053-2273

\section{Contribution}

Elena I. Melnikova consultation during the study

Ekaterina V. Bogdanova wrote the manuscript, correct it before filing in editing and is responsible for plagiarism

\section{Conflict of interest}

The authors declare no conflict of interest.

\begin{tabular}{ccc}
\hline Поступила 12/11/2020 & После редакции 23/11/2020 & Принята в печать 01/12/2020 \\
\hline Received $12 / 11 / 2020$ & Accepted in revised 23/11/2020 & Accepted 01/12/2020 \\
\hline
\end{tabular}

